\title{
The Problem of Latin American Cultural Synthesis in the Reflection of the Russian science*
}

\author{
Olga Bondar \\ Department of Social Philosophy \\ Faculty of Humanities and Social Sciences \\ Peoples' Friendship University of Russia (RUDN University) \\ 6 Miklukho-Maklaya St, Moscow, 117198, Russian Federation \\ E-mail: bondar_oyu@rudn.university
}

\begin{abstract}
The complexity of the culture formation in Latin America has led to the emergence of two approaches to the assessment of its cultural power in the Russian humanities: negativist and apologetic ones. The author of the article leaves out the explanatory schemes in which Latin American culture is theoretically non-existent, and proposes to consider the positions of the Russian researchers, who recognize the possibility of intercultural interaction, and, consequently, the reality of cultural synthesis in Latin America.
\end{abstract}

Keywords-culture formation; synthesis; Russian Latin American studies

\section{INTRODUCTION}

Latin America came in sight of the Russian scholars in the late 19th century. However, the formation of the region's broad research front began in the 1960s, when Latin American studies formed as an integrated scholar discipline, bringing together the experts from various fields. The discrepancy of the degree of elaboration of theoreticalmethodological bases to the complexity of the object being studied was a serious obstacle for a number of representatives of the humanitarian branch of this direction of scientific knowledge. The merit in overcoming the said situation belongs to the Russian philologists and literary scholars V.N. Kuteyshikova, I.A. Terteryan, V.B. Zemskov, Y.N. Girin, and A.F. Kofman. Their works went beyond the literary studies and turned into large-scale cultural studies, which became a reference not only for the literary but also for historical, cultural and philosophical scholars.

\section{CUltural Genesis in LAtin AmericA AS the PROBLEM}

The peculiarity of the Latin American cultural-historical community, resulting from the interaction of heterogeneous and multi-stage cultural layers and traditions - indigenous and Iberian ones, gave the Russian researchers an impact on bringing to the fore the problem of cultural genesis and

*This paper was financially supported by the Ministry of Education and Science of the Russian Federation on the program to improve the competitiveness of Peoples' Friendship University of Russia (RUDN University) among the world's leading research and education centers in the 2016-2020. conjugated problem of "cultural synthesis". The latter one became a hub, creating an ongoing debate.

Reduced to the need of defining the mechanisms and strategies for producing the new quality, that may be called "Latin American", the problem demanded a number of clarifications of theoretical order:

- Defining semantic field of the term "cultural synthesis";

- Setting the question of possibility/impossibility of the (culture) generating type of interaction;

- Setting the borders, limits of interaction in the case of heterogeneous cultural traditions encountered in the New World.

III. THE PHENOMENON OF LATIN AMERICAN CULTURAL SYNTHESIS: ATTEMPT OF A THEORETICAL SUBSTANTIATION

Original Russian Latin American studies viewed the "cultural synthesis" process as a specific culture-forming mechanism best described by the formula "everything is mixed with everything" [1. P. 370]. Hence the cultural synthesis notion being identical to the notion of "miscegenative" / "mixed" culture. The latter one, determined in the works of the writer el Inca Garcilaso de la Vega (end of the 16th - early 17th century) [cf. 2. P. 316334], was firmly entrenched in the continental culturalphilosophical thought until the 20th century. The concepts of "miscegenative culture", "miscegenative continent" recorded polymorphic and "derivative" character of the Latin American world but simplified unacceptably the described actual process of culture genesis. Hence the tendency to consider a complex problem, not liable to unambiguous and simplistic solutions, was bound to cause objections stemming from the Russian researchers.

A.F. Kofman's position is representative in this respect. His criticism of the "cultural miscegenation" theory may be reduced to the following:

- It is inadmissible to equate racial and cultural origins;

- It is necessary to question the thesis about the equivalence of the participants; 
- The concepts of "cultural synthesis" and "cultural miscegenation" require clear specification and differentiation [3. P. 393-398].

The Russian Latin American scholars' position on the concept of "cultural synthesis" were divided in the process of terminology development. One group of researchers understood the "cultural synthesis" as the "long-term historical and cultural process, advancing in the result of intercultural interaction, in which there is a new cultural system is born", while the other group saw "cultural synthesis" as "the specific mechanisms of intercultural interaction and the generation of new cultural forms" [4. P. 7].

Referring to the meaning of the "cultural synthesis" concept in both the aforementioned versions, the Russian literary and Latin American scholar V.B. Zemskov defined the boundaries of its application for "interpreting and fingerprinting cultural genesis" [5. P. 505]. From his point of view, this concept is not acceptable when discussing specific levels and types of culture - areas and specific forms of cultural genesis, as there are a variety of mechanisms (imposition, translation, transcription, assimilation, syncretization, recoding), and synthesis is only one of the possible variants.

The concept of "cultural synthesis" is justified in extreme points of culture - the lowest and the highest: on the level of biological "soil" (racial-ethnical processes) and the associated forms of material culture, socio-economical areas, the structures of everyday life and on the higher forms of spirituality (Weltanschauung, ideology, etc.). As for the middle level, it doesn't work with full dedication and needs refinement.

The researcher offers an interpretation of "cultural synthesis" concept, considering the different cases of cognitive situations and contexts, as a "way to measure and define macro evolutional processes on a universal level, which result in an emergence of new civilizations; it is a process, not the result in relation to the historical development" [1. P. 369]. The researcher offers the following demand as the methodological one - "to study specific processes of cultural genesis on the different levels of historical and cultural formation, one shall differentiate the concept and study particular culture-forming mechanisms" [1. P. 369].

The Russian literary and Latin American scholar Y.N. Girin doubts the possibility of applying the cultural synthesis concept, considering it to be exogenous and Eurocentric. Taking the contraposition, he offered to replace the cultural synthesis concept with "modeling" / "construction" and "integrity" [cf. 6. P. 42-54] - concepts, reflecting, from his point of view, the strategy of Latin American's culture selfbuilding. Arguing with such a position, the latter, incorporating the "fragments of almost all world cultures" [7. P. 425], is a result of their coexistence, conflux, recombination, and not the emergence, disappearance, and transformation of the original fragments, as suggested by V.B. Zemskov. More suitable for its reflection are the concepts of "mix" and "eclecticism", that emphasize the (in principle) impossibility of implementing the synthetic forms of cultural genesis. Sharing the opinion of the Latin American authors, not absolutely taking the aforementioned concept, Y.N. Girin comprehends it purely as a special case, not a general principle, guiding the process of cultural genesis.

The Russian Latin America historian Y.G. Shemyakin considered the cultural synthesis concept, proposed by V.B. Zemskov, to be overloaded in terms of content and showed its limitations in the case of studying the specific mechanism of cultural interaction in the defined chronological boundaries. Finding reference in the Hegelian understanding of synthesis, Shemyakin reviews synthetical buildups as more complicated and rare phenomena, qualitatively different in their parameters and characteristics from those that arise because of mixing (culturally) heterogeneous elements. He suggests interpreting cultural synthesis as a process of the interaction of cultures, leading to the formation of a new reality, qualitatively different from that originally entered the interaction of human worlds. The defining principle of this type is its generative character, having an impulse, stimulating a new reality for further development.

The result of applying that concept to the Latin American reality was the subsequent differentiation process of the interaction of cultures. Describing them by the triad of concepts "confrontation - symbiosis - synthesis", the Russian scholar explicated their content using the historical material, fixing the chronological boundaries and their zones of action. The formation of the synthesis type of interaction was happening in form of transition from rejection-confrontation to repressive forms of cultural models' transplantation (La Conquista epoch), to the subsequent contact - co-presence of the cultural worlds, in which they, continuing being themselves, were forming an indissoluble unity (17th century); and forth to a new (cultural) quality, which was emerging in the areas of traditions' contact (between the end of the 18th to the 19th century). Considering the synthesis through the prism of the Hegelian approach, the researcher introduces it as "the process of creating a new quality, but it is not the quality" [8. P. 107]. Hence, the area of occurrence, in which the symptoms of the new were formed, are defined as a phase of symbiosis.

The formation of the synthetical type of interaction was accompanied by complications in form of the two other types - symbiosis and confrontation - that were an obstacle to synthesis. Such a situation was typical for the continent as a whole, and for its particular regions. By extending the "capacity" of the concept of symbiosis as a stage of the synthesis, Y.G. Shemyakin raised the question about the exposure of the culture genesis process because of the incompleteness and insufficiency of the cultural synthesis.

\section{THE PROBLEM OF CULTURAL SYNTHESIS IN RELATION OF THE BORDERLINE CIVILIZATIONS CONCEPT}

Linking up theoretical and methodological resources of the civilizational discourse to the problem of cultural synthesis has contributed to a better understanding of the 
Latin American phenomenon and to clarification of its civilizational status in the global historical process. The question of heterogeneity of civilizational formations in terms of their historically imposed differences resulted in the division of objects into classical - formed monoliths (subecumenism) - and non-classical "borderline" ("splice", "threshold", etc.) ones. Thus, Western Christian, Indian, Chinese, Islamic civilizations are counterpoised to Latin American civilization along with the typologically close Iberian and Russian ones.

Classification of Latin America as a borderline formation influenced its subsequent interpretation, associated with the emergence of the two approaches - static (ontological) and dynamic (historical). The Russian scholars, developing the static approach [cf. 9. P. 96-103; 10. P. 96-114; 11. P. 233243], explained classical objects as synthetical phenomena, and borderline objects, because of the process' incompleteness, as symbiotic phenomena.

Abandoning the static approach in favor of dynamic one, V.B. Zemskov changes the cognitive strategy and develops his own explanatory model within the boundaries of the broad historical context, entitled "Big Time". In "Big Time", considering the historical dynamics, the concept of the borderline changes the status of the referred phenomenon from historical "fault" into $"<\ldots>$ bridges $<\ldots>$ engineering structures of history" [12. P. 20], changing the understanding of the cultural genesis process, revealing the limitations of the conceptual and descriptive tools. For Latin America, the concept of "symbiosis-synthesis" doesn't "cover" the case, concerning "high" examples of artistic consciousness. There we are dealing with "not symbiosis, namely with synthesis" [1. P. 378]. The peculiarity of the Latin American phenomenon is defined by the fact that its development is supported by the existing "core", potent of synthesis.

The existence of the synthesizing system in Latin American variant is seen also by the literary and Latin American scholar A.F. Kofman, who defines it as "tradition" - i.e. "the creation of a sustainable system of artistic archetypes" [13. P. 37], representing the national view of the world. Hence, the essence of cultural synthesis - a search, the invention of what could be called Latin American "logos", own conceptual and artistic language. Creative impulse of synthesis finds its expression in aesthetics, philosophy, and, finally, in the existential modes of Latin American culture.

The dynamic (historical) approach shows a different understanding of Latin American version of borderline - not as an ontologically given, but of a temporary nature. This changes the view of Latin America, as it appears to be the cultural and civilizational phenomenon, having general synthesizing quality.

\section{CONCLUSION}

Pairing the problem of cultural synthesis with the phenomenon of civilizational borderline, brought to the forefront of the research the requirement of the versatile comprehension and multi-layered approach to the problem's solution. As for the arising methodological counterpoints, it seems that the vectors of the solution's search in the global civilizational field are divergent but not mutually exclusive. They represent themselves as complementary (possible) interpretations of the multidimensional phenomenon of Latin America, revealing its cultural potential and mechanics, considering different attitudes and perspectives - making the stress on scarcity, weakness of the system, its uncertainty, and actualizing the question of its constructive-creative qualities.

\section{REFERENCES}

[1] Zemskov V.B. From the Study of the Literary Process to Understanding the Civilizational Paradigm // Latin American Culture in the Discussions of the 20th - early 21 st century. - M.: IMLI RAN, 2009.

[2] Kuteyshikova V.N. Creative Works of el Inca Garcilaso de la Vega // History of the Literatures of Latin America. From the Earliest of Times till the Beginning of the Independence War. Vol. 1. - M.: Nauka, 1985

[3] Kofman A.F. The Problem of Synthesis in the Latin American Culture // Latin American Culture in the Discussions of the 20th early 21 st century. - M.: IMLI RAN, 2009.

[4] Zemskov V.B. Introduction. On Inter-Civilization Interaction // Iberica Americans. Mechanisms of Culture Genesis in Latin America. - M.: Nauka, 1994.

[5] Zemskov V.B. On Literature and Culture of the New World. - M. Center for Humanitarian Initiatives, 2014

[6] Girin Y.N. To the Question of Self-Identification Models of Latin American Culture // Mechanisms of Culture Genesis in Latin America. - M.: Nauka, 1994.

[7] Girin Y.N. Was there a Synthesis? // Latin American Culture in the Discussions of the 20th - early 21st century. - M.: IMLI RAN, 2009.

[8] Shemyakin Y.G. At the Origins of the Cultural Synthesis Process: The Interaction of Spanish and Indian Worlds in the Age of Discovery and Conquest of America // America after Columbus: the Interaction between two Worlds. The Problems of Indian Studies. M.: Nauka, 1992.

[9] Zemskov V.B. Latin America and Russia. The Problem of Cultural Synthesis in Borderline Civilization // Social Studies and Modernity. 2000. - №5.

[10] Shemyakin Y.G. Peculiarities of the "Borderline Civilizations": Latin America and Russia in Historical Comparative Light // ONS. - 2000. - №3.

[11] Yakovenko I.G. The Problem of the Scientific Method in Civilizational Studies // Civilizational Studies. Resp. Editor B.I. Koval. - M.: ILA RAN, 1996.

[12] Zemskov V.B. Civilizational and Cultural Borderland - Universal Constant and Means of Self-Creation of the Global HistoricalCultural Process // Problems of Cultural Borderlands. In Memoriam V.B. Zenskov (1940-2012). - M.: IMLI RAN, 2014.

[13] Latin American Civilizational Unity in the Globalizing World. In 2 Vols. Vol. 1 - M.: IMEMO, 2007. 